DOI 10.37882/2223-2982.2020.08.09

\title{
ПОЛИФУНКЦИОНАЛЬНОСТЬ ДИСКУРСИВНОГО СЛОВА ХОРОШО В УСТНОМ НАУЧНОМ ДИСКУРСЕ (НА МАТЕРИАЛЕ ВУЗОВСКИХ ЛЕКЦИИ) ${ }^{1}$
}

\section{THE MULTIFUNCTIONALITY \\ OF THE DISCURSIVE WORD XOPOШO \\ IN ORAL SCIENTIFIC DISCOURSE (BASED ON MATERIAL FROM UNIVERSITY LECTURES)}

\section{Wang Lina}

Summary: The article presents an attempt to describe the multifunctionality of xорошо as a discursive word in oral scientific discourse based on the material of university lectures. The purpose of these studies is to analyze in detail, on the basis of real material of a tape recording, the organizational and regulatory functions performed by this discursive word in a specific context. Scientific novelty lies in the fact that for the first time a comprehensive analysis of the functioning of xopomo as a discursive word in oral scientific discourse, especially on the material of university lectures, has been undertaken.

Keywords: xopomo as a discursive word; oral scientific discourse; university lectures; multifunctionality; signal-organizer and signal-regulatory.
K ак известно, термин «дискурсивные слова» в русистике заимствован с французского сочетания mots de discours, предложенного французским лингвистом Culioli (1990). А активное специальное изучение данных дискурсивных единиц началось с 1990-х годов после издания монографии «Путеводитель по дискурсивным словам русского языка» [Баранов и др., 1993], и двух сборников - «Дискурсивные слова русского языка: опыт контекстно-семантического описания» и «Дискурсивные слова русского языка: контекстное варьирование и семантическое единство», написанных под руководством К. Киселёвы и Д. Пайара [Киселёва и др., 1998; 2003]. Надо сказать, что эти три работы значительно способствует исследованию дискурсивных слов с разных аспектов в русской лингвистике. В дальнейшем на соответствующие идеи из них опираются в своих работах многие ученые данного дискурсивного явления [Викто-
Ван Лина

Аспирант, Пекинский университет иностранных языков

(2. Пекин, КНP)

linawang0122@sina.com

Аннотация: В статье представлена попытка описания полифункциональности «хорошо» как дискурсивного слова в устном научном дискурсе на материале вузовских лекций. Цель данных исследований - подробно проанализировать на основе реального материала магнитофонной записи выполняемые организаторские и регулировочные функции данным дискурсивным словом в конкретном контексте. Научная новизна заключается в том, что впервые предпринят всесторонний анализ функционирования «хорошо» как дискурсивного слова в устном научном дискурсе, особенно на материале вузовских лекций.

Ключевые слова: «хорошо» как дискурсивное слово; устный научный дискурс; вузовские лекции; полифункциональность; сигнал-организатор и сигнал-регулятив. рова, 2008; 2014; 2016; Кобозева, 2007; Плугян, 2013; 2014 и мн. др.], в том числе некоторые китайские (см. [Сюй Хун, 2012; Ци Фанси, 2018]).

Мы знаем, что M.A.K. Halliday выделил 3 макрофункции языка, это идеационная (ideational), межличностная (interpersonal) и текстуальная (textual) функции [Halliday, 1970a, с. 174-175]. Что касается дискурсивных слов (или дискурсивов), то они в основном выполняют вторую и третью функции, а идеационная функция, как нам кажется, может присутствовать в дискурсивах лишь в сочетании с двумя другими - текстовой и межличностной. И с идеей Хэллидея соотносятся 3 типа информации, выделяемые С.В. Андреевой - фактуальная, коммуникативная и дискурсивная информации [Андреева, 2005, с. 84]. Вслед за Андреевой, Е.Ю. Викторова считает, что дискурсивы участвуют в передаче дискур-

\footnotetext{
1 Работа выполнена при финансовой поддержке проекта центральных университетов (в рамках научно-исследовательского проекта «Общественный ритуальный дискурс и ритуальный дискурс об отношениях между людьми», проект № 2019JХ010) И проекта совместной подготовки аспирантов внутри страны и за рубежом.

本文受 “中央高校基本科研业务费专项资金” 资助和 “北京外国语大学北京高等学校国内外联合研究生培养基地项目” 资 助。
} 
сивной (или организаторской) и коммуникативной (или регулятивной) информации [Викторова, 2016, с. 90]. Таким образом, системно-функциональная теория Хэллидея и идеи о типах информации Андреевы и Викторовы составляют теоретическую базу для анализа полифункциональности дискурсивного слова хорошо в настоящей работе. И практическая значимость нашей работы заключается в том, что полученные результаты исследования могут применимы в анализе устного научного дискурса, также послужить преподаванию русского языка как иностранного и составлению словаря. Следует отметить, что объяснения о хорошо, представленные в словаре, обычно не указывают конкретный контекст, в котором оно используется, и особенности использования данного слова описаны в научной литературе далеко не полностью. В этом состоят актуальность выполненной работы.

В процессе нашего анализа в основном использовались 3 типа методов исследования: контекстно-описательный метод, метод дискурсивного анализа, а также метод количественного и качественного анализа.

Для достижения поставленной цели необходимо решить следующие задачи: 1. выявить полифункциональность слова хорошо на разных уровнях во вузовских лекциях. 2. проанализировать выполняемые хорошо как дискурсивным словом функции в конкретном контексте. 3. объяснить десемантизацию данного дискурсивного слова.

Как пишут ученые, дискурсивные слова «не образуют «естественный» класс единиц» [Киселева и др., 1998, с. 9], то есть это особая транскатегориальная система речевых единиц, что с одной стороны «объединяет единицы, которые традиционные классификации относят к различным частям речи (частям, наречиям и др.)» [там же]. А с другой, этот класс включает в себя не только частицы, наречия, вводные слова и другие так называемые «классические» дискурсивы, но и многие речевые единицы «синкретичного типа», как авторизующие конструкции, акцентивы, средства адресации и др., которые совмещают вспомогательные и основные фактические информации [Виктрова, 2016, с. 57]. К тому же, данный класс не имеет четких границ, принадлежность слова или конструкции к классу дискурсивных слов определяется главным образом «на основании функциональных критериев» [Киселева и др., 1998, с. 9], т. е. обеспечивать связность, логичность и структурность дискурса, и регулировать отношения между коммуникантами. Дискурсивы, действительно, это очень сложная функциональная система на уровне дискурса. Неудивительно, что Плугян так сказал: «Дискурсивные слова, это последний бастион грамматики, и если он нам сдастся, тогда уже точно можно сказать, что грам- матику мы будем знать всю» [Плугян, 2013, электронный ресурс].

Что касается полифункциональности слова хорошо, то она может проявляться на разных уровнях. С одной стороны, слово хорошо может иметь недискурсивные и дискурсивные употребления в устном научном дискурсе. Например (в связи с тем, что лекция считается одним из наиболее распространенных жанров в сфере устного научного общения [Скорикова и др., 2017, с. 123], все приводимые в статье примеры взяты из записи лекции вузовского подготовительного курса МГУ, сделанной 11. 04. 2020 г. и 02. 06. 2020 г.):

(Лектор преподает студентов составлять предложения.)

- П. Скажите, пожалуйста, Как Иван говорит порусски?

- С. Э-э Он говорит очень хорошо.

В данном случае наречие хорошо представляет недискурсивное употребление, так как здесь это слово выражает конкретную положительную оценку уровня русского языка Ивана, используется как основная (а не вспомогательная) коммуникативная единица, т. е. передает фактуальную информацию и выполняет роль члена предложения.

С другой стороны, хорошо как дискурсивное слово проявляет полифункциональность на прагматическом уровне, выполняет как вспомогательная коммуникативная единица организаторскую и регулятивную функции. В нашем исследовании нас больше всего интересует полифункциональность именно второго типа.

\section{1. хорошо как сигнал приема информации и на- чала новой темы}

Дискурсивное слово хорошо, выполняющее данную функцию, по мнению И. И. Прибытка, называется «ресептивом-комменсивом» (от англ. receive и commence) [Прибыток, 1994, с. 23-24], так как оно используется слушающим не только в качестве реакции на речь говорящего (приема информации и завершения процесса декодирования), но и имеет правостороннее продолжение реплики, служит зачином перехода к новой теме. В этом случае, хорошо обычно находится в начале высказывания, и в то же время данная функция является наиболее распространенной в нашем материале лекционного дискурса. Например:

- П. Посмотрите, пожалуйста, «убирать» это НСВ, «убрать» это СВ. Понимаете? //- С. Э... Понимаю. //- П. Понимаете, да? Все понимают? // - С. Да. // - П. Да, хорошо, тогда давайте дальше. Читайте, пожалуйста...

- П. У кого есть вопросы? Ecть вопросы или нет воnросов? У С. есть вопросы? // - С. Hem. // - П. Hет вопро- 
сов? Хорошо, тогда давайте с вами посмотрим дальwe.

Как вы и заметили, что в этих контекстах исходнолексическое оценочное значение слова хорошо частично сохраняется, хотя лектор выражает удовлетворение от хода коммуникации, т. е. «объектом оценки является не содержание речи, а сам речевой контакт» [Викторова, 2016, с. 521], однако, на наш взгляд, здесь функция приема информации и подготовки сегментации речи в нем превалирует над оценочной, т. е. первичная функция, выполняемая дискурсивным словом хорошо в данных случаях, как нам кажется, это организаторская функция, поэтому мы условно его относим к данному типу сигнала, хотя оно выполняет одновременно и другие прагматические функции. Поэтому мы согласны с С.В. Андреевой, что «всё в языке не имеет «китайских стен», характеризуется взаимопереходами, синкретичностью» [Андреева, 2005, с. 108]. И данный критерий тоже принят при классификации других функции дискурсивной единицы хорошо (см. ниже). В этом как раз проявляются прагматическая полифункциональность и синкретизм дискурсивов.

\section{2. хорошо как сигнал хезитации}

Как говорит лингвист В.А. Плугян, хезитация, это «очень нужное средство для построения устной речи, <...>, и средство, которое дает человеку возможность перевести дух, расслабиться, продумать конструкцию фразы, не прекращая говорить» [Плугян, 2014, электронный ресурс]. Действительно, когда хорошо используется лектором как сигнал хезитации в процессе коммуникации, обычно ориентировано на заполнение пауз, организацию своей речи и мышления или готовность обозначения границ между ее частями. По мнению Викторовой, «в лекциях главными функциями хезитативов являются связующая и поисковая, поскольку во время лекции на право говорить никто, кроме лектора, как правило, не претендует» [Викторова, 2016, с. 198]. Теперь приведем примеры использования хорошо с данной функцией.

(студент прочитал предложение.)

- П. Хорошо, Так, видите, это тоже падеж три, да? Это тоже падеж три. Хорошо. Дальше. Пожалуйста, чumaŭme $C$....

- П. Праздник фонарей, я вам сейчас скажу, значит, праздник фонарей, фонарей, сейчас переводчик, Юань Сяо Цзе. ... Хорошо, э-э-э значит, давайте с вами посмотрим дальше.

Мы увидим, что в этих двух примерах в левой контексте слова хорошо появились повторные реплики, это показывает, что говорящий в данном контексте упорядочивает и планирует свой мыслительный про- цесс или речевую деятельность. Как подчеркивает Викторова, «размышления в процессе речи, свойственны русскому национальному характеру» [Викторова, 2008, с. 30]. Кроме того, во втором примере рядом со словом хорошо также используются незаполненные паузы, «собственно коммуникатив» э-э-э [Андреева, 2005, с. 235], и маркер логического следствия значит, сигнализирующий о готовности говорящего выполнять взятые на себя коммуникативные обязательности (здесь о готовности перехода к другой теме обсуждения). Все это подтвердило то, что в этих случаях слово хорошо в первую очередь осуществляет функции заполнения пауз и планирования своего мыслительного процесса. И в то же время, присущее ему оценочное значение считаем самым слабым. Этот анализ также показывает, что дискурсивы работают на уровне дискурса.

\section{3. хорошо как сигнал стимуляции}

При обсуждении хорошо как дискурсива-стимулятива в лекциях, мы заметили, что данное дискурсивное слово часто используется в составе вопросительной конструкции хорошо?, находящаяся в конце контекстного фрагмента. Прибыток считает, что стимулятивы «стимулируют собеседника к вступлению в общение», т. е. вовлекают слушающего в ход рассуждения говорящего [Прибыток, 1994, с. 24]. Мы заметили, что эта дискурсивная единица может наряду с функцией стимуляции утверждать контакта с аудиторией, и имплицитно поддерживать внимание студентов на должностном уровне в лекционном дискурсе. Иначе говоря, хорошо в основном передает регулятивные информации в данном контексте. Например:

- П. Тогда в следующий раз мы вернемся к этой теме, xорошо?

- П. Ладно, давайте не будем читать. Haше домашнее задание, э-э-э значит вы с Еленой э почитали, будете читать большие тексты, да? Тексты на странице 113, 114 и 115, правильно? но еще вам нужно на завтра выучить обязательно тему, э-э не на завтра, а на четверг, тема - образование Китая, хорошо?

Необходимо отметить, что хотя в этих случаях дискурсивная конструкция хорошо? является прямым вопросом по форме, но лектор иногда не ожидает положительного или отрицательного ответа от аудитории. С помощью хорошо?, говорящий, с одной стороны, хочет активизировать чувство участия слушателей в рассуждении, установить и поддержать непосредственный контакт с аудиторией, а с другой, как говорит Д. Брчакова, данные средства непосредственного обращения к адресату «создают благоприятную атмосферу в аудитории, способствуют некоторой интимизации общения, повышают роль говорящего как индивидуума» [Брчакова, 1995, с. 22]. 
К тому же, мы увидим, что во втором примере, помимо хорошо?, выполняют аналогичные функции и другие так называемые «актуализаторы» [Викторова, 2016 , с. 229], в том числе конструкции да? и правильно?. Объективно говоря, такие стимулирующие реплики выполняют очень важную роль в устном научном дискурсе. Они имеют большое значение для общения в кооперативном ключе. В такой обстановке студенты чувствуют себя более комфортно, что необычайно важно для успешного учебного процесса и полноценного усвоения материала лекции. Конечно, вся заложенная в дискурсиве информация может передаваться и основными коммуникативными единицами. «Однако, именно в дискурсивных словах информация, организующая дискурс, эксплицируется в наиболее лаконичном, концентрированном виде» [Андреева, 2005, с. 102]. Можно сказать, что «естественный русский дискурс без этих слов будет выглядеть суховато, дистиллипрвано» [Плугян, 2013, электронный ресурс].

\section{4. хорошо как сигнал оценки}

Как мы уже упомянули выше, положительное оценочное значение, это исходное значение слова хорошо. Когда оно выполняет роль члена предложения, т. е. предложение не может обойтись без этого слова, тогда не появилось ослабление или отсутствие у этого дискурсива исходного лексического значения, и представляет недискурсивное употребление.

Но следует отметить, что в некоторых случаях слово хорошо не только отражает активное речевое действие собеседника, но и одновременно передает насыщенный субъективно-модальный характер. В такой обстановке, на наш взгляд, все же можно его включить в рамку дискурсивов, но только занимает более периферийное место, т. е. находится на переходном зоне между дискурсивным и недискурсивым употреблением. Приведем примеры:

(Студент правильно ответил на вопрос.)

- П. (Лектор повторит ответ студента) Да, Раньше в школе тратили свободное время. Хорошо, молодеи, молодец! Видите, С., ну вы же хорошо можете отвечать, вы можете хорошо заниматься этой частью. Так...

(Студент прочитал предложение.)

- П. Хорошо, молодеи! Давайте дальше.

Можно заметить, что в этих двух случаях слово хорошо отражает удовлетворительное речевое поведение студентов, и в то же время, передает эмоциональнооценочную реакцию и субъективное мнение, и отношение лектора к нему (здесь лектор непосредственно выражает студенту похвалу, т. е. «Я хвалю вас за хорошее чтение.»). К тому же, для усиления той интенции, наряду со словом хорошо используется и другая с аналогичной функцией дискурсивная единица молодец. Исходя из этого, мы рассматриваем слово хорошо в таких ситуациях как синкретичный дискурсив. К тому же, И.А. Шаронов отмечает, что такой функциональный класс единиц называет «коммуникативами» [Шаронов, 2020, электронный ресурс], которые действуют только как ответные реплики, и отражают искусство современной русской диалогической речи.

Как показал анализ наших материалов, хорошо как дискурсивное слово выполняет организаторскую (сигнал приема информации и начала новой темы, сигнал хезитации) и регулятивную (сигнал оценки и сигнал стимуляции) функции, они в основном появляются в речи лектора. Это естественно, т.к. лектор как управитель лекции, посредством таких «слов-помощников», как хорошо, он может регулировать общение с аудиторией, проверять работу канала связи с аудиторией, создать кооперативную и комфортную среду общения, и более эффективно выполнить свои учебные задачи. Кстати, дискурсивные слова 好(хао) в китайском языке и ок (окей) в английском существуют аналогичные функции, и сравнительный анализ может быть проведен в дальнейших исследованиях.

Мы и заметили, что когда дискурсивное слово хорошо используется как сигнал оценки (см. пункт 4), его лексическое значение сохраняется в наибольшем степени. А в том случае, когда оно работает как сигнал хезитации в дискурсе (см. пункт 2), его лексическое значение наиболее сильно утрачено, иными словами, оно имеет наивысшую степень десемантизации. Об этом мы согласны с Андреевой, что «Степень десемантизации знаменательных лексем находится в соответствии со степенью их дискурсивизации» [Андреева, 2005, с. 127]. Как указано выше, Мы разделили дискурсивы на «классические» и «синкретичные». Данное разделение именно основано на рассмотрении разных степеней их десементизации и грамматикаликации. И в то же время, «десемантизацию следует считать основной причиной полифункциональности дискурсивов» [Викторова, 2014, с. 20].

Итак, изучение полифункциональности хорошо в устном научном дискурсе на материале вузовских лекций позволяет прийти к следующим выводам:

1. Полифункциональность слова хорошо проявляется на разных уровнях, оно имеет недискурсивные и дискурсивные употребления. В том случае, когда это слово используется как основная коммуникативная единица, т. е. выполняет роль члена предложения, тогда представляет недискурсивное употребление. А в другом случае, хорошо как вспомогательная коммуникативная единица вы- 
полняет организаторскую и регулятивную функции.

2. хорошо как дискурсивное слово в основном работает как сигнал приема информации и начала новой темы, сигнал хезитации, сигнал оценки и сигнал стимуляции в нашем материале. Эта классификация основана на первичной доминирующей функции дискурсивного слова хорошо в кон- кретной ситуации использования.

3. Десемантизация считается основной причиной полифункциональности дискурсива хорошо. В результате десемантизации осуществляется возможность его изучения только через употребление, в этом проявляется и нестабильность класса дискурсивов.

\section{ЛИТЕРАТУРА}

1. Андреева С.В. Элементарные конструктивко-синтаксические единицы устной речи и их коммуникативный потенциал: дис. ... докт. филол. наук: 10.02 .01 / С. В. Андреева.-Саратов, 2005. - 347 с.

2. Брчакова Д. Коммуникативные и структурные типы связей между смежными предложениями в устном научном тексте / Д. Брчакова // Современная русская устная научная речь. - М.: Филолог. фак-т МГУ, «Филология», 1995. - С. 20-45.

3. Баранов А.Н. Путеводитель по дискурсивным словам русского языка / А.Н. Баранов, В.А. Плунгян, Е.В. Рахилина. - М.: Помовский и партнеры, 1993. - 207 с.

4. Викторова Е.Ю. Вспомогательные коммуникативные функции в речи российских и американских президентов (на материале жанра послания) / Е.Ю. Викторова // Известия Саратовского университета. Филология. Журналистика. - 2008. - № 2. - С. 22-31.

5. Викторова Е.Ю. Прагматическая полифункциональность дискурсивных слов / Е.Ю. Викторова // Вестник Воронежского государственного университета. -2014. - № 2. - C. 18-22.

6. Викторова Е.Ю. Вспомогательная система дискурса: проблемы выделения и специфики функционирования: дис. ... докт. филол. наук: 10.02.19 / Е.Ю. Викторова. - Саратов, 2016. - 617 с.

7. Киселева К. Дискурсивные слова русского языка: опыт контекстно-семантического описания / К. Киселева, Д. Пайар. - М.: Метатекст, 1998. - 447 с.

8. Киселева К. Дискурсивные слова русского языка: контекстное варьирование и семантическое единство / К. Киселева, Д. Пайар. - М.: Азбуковник, 2003. -207 c.

9. Кобозева И.М. Полисемия дискурсивных слов и возможности ее разрешения в контексте предложения (на примере слова вот) / И. М. Кобозева // Труды Международного семинара ДИАЛОГ 2007 по компьютерной лингвистике и ее приложениям. - 2007. - С. 250-255.

10. Прибыток И.И. Сентенсоиды: структура, семантика. Прагматика. Сферы функционирования (На материале англ. яз.): автореферат дис. ... доктора филол. наук: 10.02.04 / И. И. Прибыток. - Санкт-Петербург, 1994. - 32с.

11. Плугян В.А. 0 дискурсивных словах, их роли в нашей речи и бесполезности борьбы с ними [Электронный ресурс] / В.A. Плугян. — 2014. — URL: https:// barucaba.livejournal.com/89916.html (дата обращения: 15.12.2019)

12. Плугян В.А. Дискурсивные слова: 7 фактов о богатстве значений слов-паразитов [Электронный ресурс] / В.А. Плугян. - 2013. — URL: https://postnauka. ru/video/2961 (дата обращения: 15.12.2019)

13. Скорикова Т.П. Жанровые особенности устной научной коммуникации: концепция лингвистического описания / Т.П. Скорикова, Е.А. Орлов // Вестник СВФУ. 一 2017. 一 № 5 (61). - С.117-128.

14. Шаронов И.А. Коммуникативы в русском речевом этикете // Труды международной научно-практической конференции «русский язык и литература в славянском мире: история и современность» / И.А. Шаронов. - 2020. - URL: https://rll2020.philol.msu.ru/ (дата обращения 25. 05. 2020)

15. Halliday M.A.K. Language Structure and Language Function. In Jonathan J. Webster (Ed.). On Grammar. / M.A.K. Halliday. - London: Continum International Publishing Group, 1970a. - P. 173-195.

16. 齐芳溪, 姜宏. 汉俄视觉行为动词的话语标记对比分析一一以“看/смотреть”和“见/видеть”为例 [J]. 东北亚外语研究, 2018 (4) , Р48-53. (Ци Фанси. Сравнительный анализ дискурсивных маркеровв в виде визуальных глаголов в китайском и русском языках - на примере «смотреть» и «видеть» / Фанси Ци, Хун Цзян // Изучение иностранных языков Северо-Восточной Азии. — 2018. — № 4. - С. 48-53.)

17. 许宏. 西方语言哲学与俄罗斯的语用学研究[M], 北京: 中国社会科学出版社, 2012, 297页. (Сюй Хун. Исследования западной философии языка и Российской прагматики / Хун Сюй. - Пекин: China Social Sciences Press, 2012. - 297 с.)

(c) Ван Лина (linawang0122@sina.com).

Журнал «Современная наука: актуальные проблемы теории и практики» 